\title{
Student Performance in Online Classes at a Hispanic-Serving Institution: A Study of the Impact of Student Characteristics in Online Learning
}

\author{
Rebecca S. Cottrell \\ Metropolitan State University of Denver
}

\begin{abstract}
As online enrollment increases in the United States, it is important to understand the impact of course modality on student outcomes. In particular, there has been limited research on the effect of course enrollment at Hispanic-serving institutions (HSI). The current study evaluated the effect of online course enrollment on student grades and on student withdrawal rates by comparing outcomes in online and face-to-face classes. The main innovation of this study is to use propensity score analysis to control for 15 different student characteristics as a way to control for the selection bias introduced when students self-select into different course modalities. The study used data from a large, public, HSI in the mountain west during the 20172018 and 2018-2019 academic years. Baseline results on a two-sample $t$-test indicated that online students have significantly higher course grades, and non-significantly different withdrawal rates before controlling for student characteristics. The study used a propensity score analysis (PSA) to control for 15 confounding covariates after testing three different PSA models: near-neighbor matching, Mahalanobis' metric, and optimal matching. After evaluating each model for validity and sensitivity, a near-neighbor 1:2 matching PSA shows a non-significant difference in student grades, and higher withdrawal rates in online classes than face-to-face classes. Given these results, institutions should ensure that they are providing adequate academic support for online students to improve retention and success rates for online students.
\end{abstract}

Keywords: distance education, online education, higher education, success rates, educational indicators, propensity score analysis

Cottrell, R. (2021). Student performance in online classes at a Hispanic-Serving Institution: A study of the impact of student characteristics in online learning. Online Learning, 25(3), 18-35. doi:10.24059/olj.v25i3.2853 
Over the past decades, online course enrollment in the United States has been steadily increasing. As of fall semester 2019, 16.6\% of students at degree-granting postsecondary institutions were taking exclusively distance education courses, with $35.3 \%$ taking one or more distance education courses (National Center for Education Statistics, 2019). Over the past two decades, online enrollment in the U.S. has increased from $9.6 \%$ in 2002 to $31.6 \%$ in 2016 (Allen \& Seaman, 2014; Seaman, Allen \& Seaman, 2018). In recent years, postsecondary institutions have seen an increase in online and distance learning, even with the national trend of overall enrollment decline (Seaman et al., 2018).

Given these long-term online enrollment trends, that many anticipate increasing in the wake of the 2020 pandemic (Green, 2020; Kim, 2020; McCauley, 2020), it is important to understand the impact of online course enrollment on student outcomes, particularly at Hispanicserving institutions, where there has been limited previous research. Current study of online outcomes has mixed results. Some research indicates that there is no significant difference between outcomes in online and face-to-face course enrollments (Hurlbut, 2018; Tseng \& Walsh, 2016). Contrasting publications indicate that either there is either a negative effect of online course enrollment (Gregory, 2016; Johnson \& Palmer, 2015), or a positive effect (Bunn, Fischer \& Treba, 2014; Kaupp, 2012; Verhoeven \& Wakeling, 2011).

These inconclusive results are particularly important when considering that many of these studies use an observational research design that does not account for the selection bias inherent when students self-select into different course types (Coates \& Humphreys, 2004; Koch, 2005a). Student self-selection does not allow the researcher to identify and control for student characteristics in different course modalities in a randomized control trial. Smith (2017) found only five studies that used rigorous statistical methods to control for this selection bias by examining student characteristics such as race, gender, and other demographic data during statistical analysis.

The purpose of this study is to explore online course outcomes in the form of course grades and withdrawal rates at a four-year, public, Hispanic-serving institution, using a propensity score statistical method to control for selection bias. In doing this research, the researcher controlled for 15 different student covariates, including factors related to demographic data, academic performance, and personal and family factors. The current study explores student achievement at an HSI and uses a propensity score analysis to answer two questions:

1. To what extent does enrollment in a fully online class at an HSI affect course grades for undergraduate students who complete the course?

2. To what extent does enrollment in a fully online course affect course withdrawal rates for undergraduate students at an HSI?

This paper will review the current literature in the field of online and distance education as they relate to student course outcomes. It will then explore the setting and methodology for the current study and will discuss results of the study using a propensity score statistical method to evaluate student outcomes. Finally, the paper will discuss implications of the research results on online education at HSIs. 


\section{Review of Literature}

Tinto's student integration theory $(1975,1993)$, and Rovai's subsequent student integration model (2003) both suggest that student characteristics such as demographics, academic performance, and institutional and motivational factors all contribute to their course outcomes and persistence in higher education.

Additionally, there is a large body of research related to student outcomes in online spaces, with mixed results regarding the effect of online course enrollment on student course outcomes (Bunn et al., 2014; Gregory, 2016; Johnson \& Palmer, 2015; Kaupp, 2012; Verhoeven $\&$ Wakeling, 2011). However, little current research in the field of online learning specifically controls for selection bias by examining the characteristics suggested by student integration theory (Rovai, 2003; Tinto, 1975, 1993) and their impact on online course outcomes.

\section{Student Outcomes for Hispanic Students in Higher Education}

The National Center for Education Statistics (2012) indicates that Hispanic students have lower persistence rates, with only $52 \%$ earning some type of degree or certification after five years of post-secondary education. This rate was $21 \%$ lower than the persistence rate for White students. This disparity implies long-term inequity in employment, salary, and earning potential.

Hispanic students benefit from attending an HSI, which provides a positive culture that is more conducive to student success, particularly when first-generation students, or those with lower parental education, lack the social capital to succeed at other institutions (Crisp \& Nora, 2010; Hurtado \& Ponjuan, 2005). Exelencia in Education (2019) suggests that over the past decade, there has been a steady increase in the number of HSIs. This designation allows institutions to request additional funds to help support Hispanic students. However, additional evidence suggests that attending an HSI has no significant impact on Hispanic student performance and retention (Flores \& Park, 2015; Kelly, Schneider, and Carey, 2010).

This literature review explores the impact of a variety of student factors in online success rates as suggested by Tinto $(1975,1993)$ and Rovai (2003). It will also review current literature as it relates to online student outcomes at Hispanic-serving institutions.

\section{Student Outcomes in Online Classes}

Literature related to statistical outcomes in online classes provides mixed results, with some research suggesting that there is no significant difference between student outcomes in online and face-to-face classes, while other research suggests that there is either a positive or a negative effect of enrollment in online classes. The first group of research suggesting no significant difference between online and face-to-face course outcomes is consistent with Russell's (1999) no significant difference phenomenon. Many of the studies that found no significant difference between outcomes in different course modalities use a small sample in discipline-specific research that focuses on a specific subject (Dellana, Collins, \& West, 2000; Euzent, Martin, Moskal, \& Moskal, 2011; Gutierrez \& Russo, 2005; Leasure, Davis, \& Theivon, 2000; McDonough, Roberts, \& Hummel, 2014; Reuter, 2009; Rivera \& Rice 2002; Summers, Waigandt, \& Whittaker, 2005; Tseng \& Walsh, 2016; Waschull, 2001; Werhner, 2010).

Other research, including several studies with larger data sets, suggests a significant difference between online and face-to-face student outcomes. In some instances, students enrolled in face-to-face classes recorded better outcomes than did online students (Arias, Swinton, \& Anderson, 2018; Bunn et al., 2014; Coates \& Humphreys, 2004; Johnson \& Palmer, 2015; Kaupp, 2012; Verhoeven \& Wakeling, 2011). At the same time, another body of research found that online students outperformed face-to-face students (Amro, Mundy, \& Kupczynski, 
2015; Ashby, Sadera, \& McNary, 2011; Atchley, Wingenback, \& Akers 2013; Cavanaugh \& Jacquemin 2015; Cooper 2001; Gulacar, Damkaci, \& Bowman 2013; Jorczak \& Dupuis, 2014).

Impact of student characteristics on course outcomes. Some research about online student outcomes specifically focuses on the impact of student characteristics on their academic performance. These characteristics align with categories provided in student integration models (Rovai, 2003; Tinto, 1975, 1993), and they help to account for the selection bias inherent in student self-enrollment into college courses. Commonly examined characteristics include race, gender, age, and ACT or SAT scores. Even controlling for these characteristics, research indicates a variety of results. Some of these studies suggest that student characteristics are not significant predictors of their success (Ashby et al., 2011; Larson \& Sung 2009; Reuter, 2009). Other research found that after controlling for student covariates, there was no significant difference among online and face-to-face performance (Cavanaugh \& Jacquemin, 2015; Dellana et al., 2000; Euzent et al., 2011; LaMeres \& Plumb, 2014; Leasure et al., 2000).

Alternatively, other research suggests that after controlling for a variety of student characteristics, face-to-face students showed better outcomes than did online students (Arias et al., 2018; Bunn et al., 2014; Johnson \& Palmer, 2015; Kaupp, 2012; Verhoeven \& Wakeling, 2011). Finally, among the research that intentionally controlled for student characteristics, some found that online students had better outcomes than face-to-face students (Amro et al., 2015; Dotterweich \& Rochelle, 2012; Koch, 2005a, 2005b; Lapsley, Kulik, Moody, \& Arbaugh, 2008). Even after controlling for one or more student characteristics that could contribute to selection bias, there is no clear pattern of student outcomes in online or face-to-face classes.

Despite Tinto $(1975,1993)$ and Rovai's $(2003)$ assertion that student characteristics have an impact on performance and retention, it is difficult to draw strong statistical conclusions about student performance and the causality of online enrollment because students self-select into different course types, and observational studies have no way to control for these characteristics. Coates and Humphreys (2004) suggest that "self-selection into online classes is an important issue in the assessment of the effectiveness of online education. . . . Failure to account for the effects of selection leads to biased and inconsistent coefficient estimates" (p. 545). One way to evaluate the effect of student characteristics in an observational study is to use a propensity score statistical analysis.

\section{Propensity Score Analysis}

The propensity score analysis (PSA) is a statistical method that allows the researcher to control for many different variables included in observational datasets. Rosenbaum and Rubin (1983) suggested that this could be a way to estimate causal effects in this type of data. Random control trials are not always ethical or practical and PSA allows the researcher to estimate causality using a list of possible confounding covariates. The statistical results reveal imbalance between treatment and control groups and can estimate treatment effect through correcting this type of imbalance.

For this literature review, the researcher found only six studies that specifically use a PSA method to evaluate the effect of online course enrollment on student course outcomes. These studies provided a rigorous statistical analysis of student data, and all found a negative effect of online course enrollment: online students had higher withdrawal rates than did face-toface students (Smith, 2017; Wladis, Conway, and Hachey, 2015; Xu and Jaggars, 2011a, 2011b, 2013, 2014). They also earned lower course grades than face-to-face students (Smith, 2017; Xu and Jaggars, 2011a, 2011b, 2013). Despite the inconsistencies in other research that did not use a rigorous statistical method to control for a wide variety of factors, when researchers used a PSA 
to control for these covariates, they were unanimous in finding a negative effect of online course enrollment.

\section{Online Outcomes at Hispanic-Serving Institutions}

Although there has been a large body of research exploring course outcomes in online and face-to-face classes, the author found only two articles specifically focused on outcomes at HSIs. In one study, online students had better outcomes than face-to-face students (Wladis et al., 2015), while the other did not explore specific outcomes, but did find that age and ethnicity contributed to student success (Camara, 2016). The limited number of research studies that rigorously control for student characteristics, combined with the paucity of literature related to online student outcomes at an HSI suggest the need for a large-scale study at an HSI that incorporates Tinto $(1975,1993)$ and Rovai's (2003) student integration characteristics with a robust statistical method.

\section{Methods}

This study used a propensity score analysis to evaluate a large, institutional dataset from Russell University (pseudonym), a four-year, public HSI in the mountain west. Russell University has a diverse student population, with $38.9 \%$ of students enrolled in one or more online class as of fall 2018, (AVP, personal communication, July 18, 2019).

\section{Data Collection}

Russell University provided a de-identified dataset with secondary data related student grades and withdrawal rates for AY 2017-2018 and AY 2018-2019. Original data included all degree-seeking, undergraduate students who had enrolled in either a face-to-face or a fully online section of a course taught in both modalities. Because many students were enrolled in more than one class, the data were aggregated, and students who were taking $75 \%$ or more online classes were assigned to the online group, while those taking $75 \%$ or more face-to-face classes were assigned to the control, or face-to-face group. Data for students in the middle $50 \%$ who took a mixed selection of classes were eliminated from the study. Finally, student cases with missing data were eliminated in a list-wise case deletion because PSA is sensitive to missing data. The final dataset included data for 7,765 students.

\section{Variables}

For this study, the treatment variable was course modality, divided into online enrollment groups (treatment) and or face-to-face groups (control). This study had two outcome variables: (a) composite course GPA for completed courses, and (b) student withdrawal rate.

The study also explored 15 confounding covariates related to student demographics, student skills, internal, and external factors based on the four categories of the student integration model (Rovai, 2003). Student characteristics included were race, gender, age, first-generation student status, veteran status, and zip code. The one variable related to student academic skills was ACT scores as the missingness rate of SAT scores was too high to include it in the study. Internal institutional factors were current GPA, a declared major, number of credits completed, and student enrollment status (full or part-time). Finally, external student factors were marital status, employment status, income bracket, and Pell grant eligibility. Controlling for these covariates allowed for a robust statistical study of the dataset based on student integration theory (Rovai, 2003; Tinto, 1975, 1993). 


\section{Data Analysis}

After collecting and coding these data, the $\mathrm{R}$ statistical package was used to conduct a series of propensity score analyses on the data. The first test conducted was a two-sample $t$-test to establish baseline data before controlling for additional variables. Next, to determine the best model fit for these data, the researcher conducted a series of three propensity score models before conducting a sensitivity analysis (Leite, 2017; Rosenbaum, 2002) to determine the robustness of each model. For this study, the three propensity score models tested were nearneighbor matching, Mahalanobis' distance metric, and optimal matching tests. After evaluation, the near-neighbor 1:2 matching technique was selected and the researcher conducted a follow-up two-sample $t$-test to evaluate the effect of course enrollment on student outcomes.

\section{Baseline Data}

\section{Results}

Prior to conducting a PSA to control for confounding covariates and estimate treatment effect, the researcher conducted baseline statistical testing to determine effect of enrollment prior to controlling for selection bias. For R1, results from a two-sample $t$-test indicated that online students had a significantly higher course GPA $(m=2.55)$, than did face-to-face students $(m=$ $2.34), t(7763)=-5.80, p<.001)$. These data suggest that prior to controlling for confounding covariates, online students outperformed face-to-face students in terms of course grades. See Figure 1.

\section{Figure 1.}

Boxplot of student GPA based on course enrollment at Russell University before PSA.

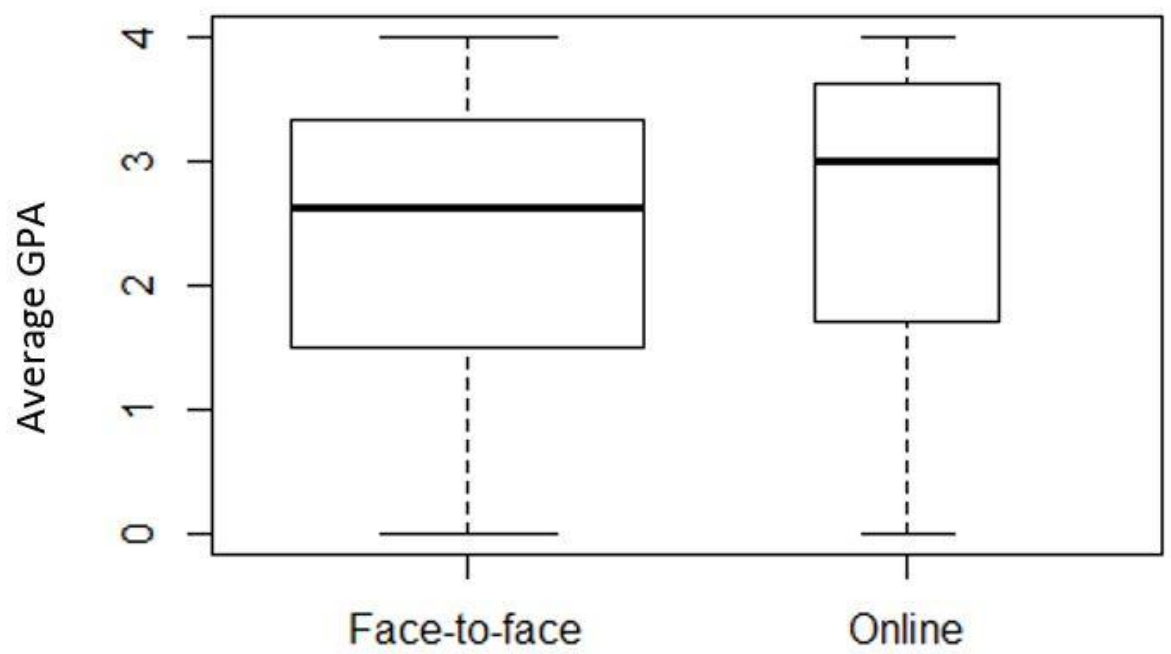

Course Modality

For R2, related to student withdrawal rates, baseline data indicated that there was no statistically significant difference between withdrawal rates among the two groups of online and face-to-face students, $t(7763)=-1.07, p=0.28)$. Together, these two baseline statistics indicate that without 
conducting a PSA, online students earned better grades than did face-to-face students, and that students in each group withdrew from classes at similar rates. See Figure 2.

\section{Figure 2.}

Bar chart of student withdrawal rates based on course enrollment at Russell University prior to PSA.

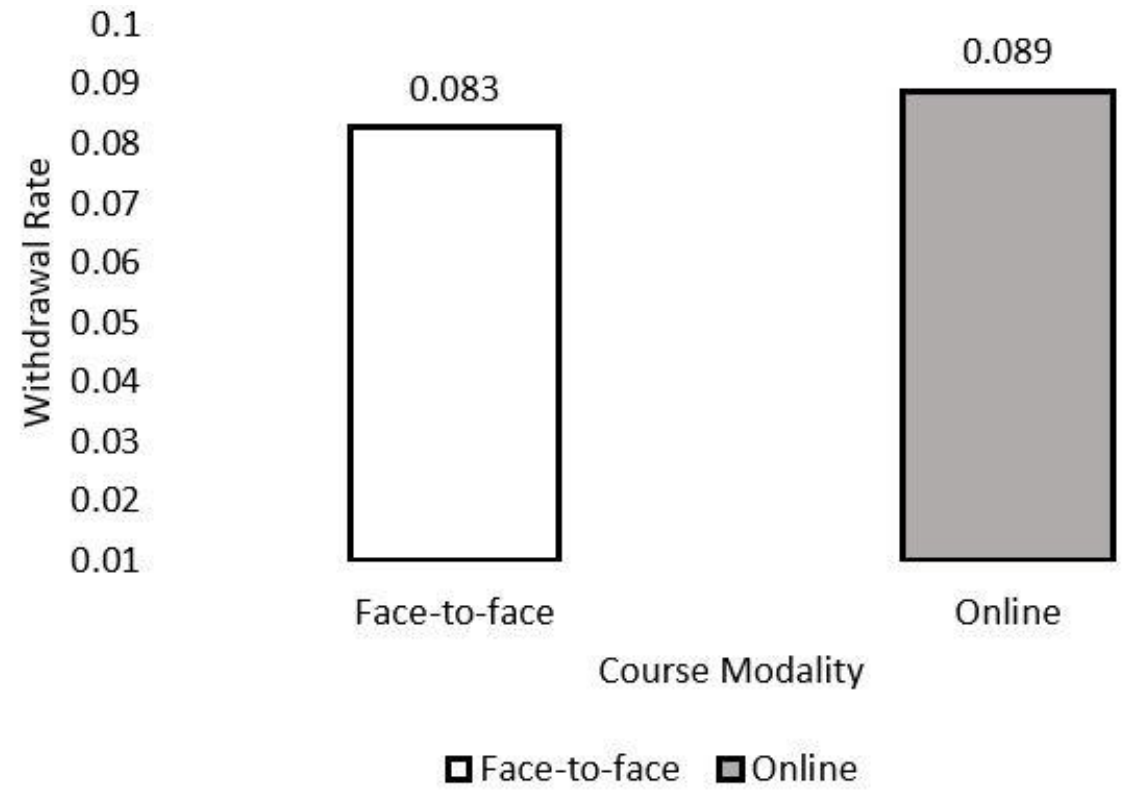

The same baseline testing also evaluated balance between online and face-to-face groups of students, by measuring the relationship between covariates and course grades or withdrawal rates. The association between these measures was statistically significant, as measured by a chi square test, $\chi^{2}(15)=1407, \mathrm{p}<.001$. This relationship indicated that eight of the 15 covariates were contributing to the significant imbalance between online and face-to-face groups. These eight contributing covariates were: number of credits earned, GPA, declared major, sex, enrollment status, ACT score, transfer status, and age.

Based on these data, the average online student profile as compared to face-to-face students at Russell is summarized as follows: $66 \%$ female; attended part-time; had higher ACT scores; was more likely to be a transfer student; was nearly one year older; had completed more credit hours; had a higher GPA; and had more frequently declared a major. These data suggested that generally, these students were older and had more academic experience than their face-toface peers. The imbalance between online and face-to-face groups on multiple variables suggested a need to control for these confounding covariates to make an accurate determination of treatment effect, and the researcher conducted a series of propensity score analyses to make that determination.

\section{Propensity Score Matching}

To reduce threats to the statistical validity of the baseline results, three different PSAs were conducted: (a) near-neighbor matching with 1:1 and 1:2 ratios, (b) Mahalanobis' distance matching, and (c) optimal matching with 1:1 and 1:3 ratios. Each of these tests showed different results, so their efficacy was evaluated by monitoring balance, retention of cases, and by using a sensitivity analysis. High sensitivity to hidden bias could suggest that these models were not a 
good fit for the data, or that they were influenced by hidden bias coming from missing covariates (Rosenbaum, 2002).

\section{Near-neighbor Propensity Score Matching}

With near-neighbor PSA and 1:1 matching, each individual in the treatment group $(n$ $=1681)$ was matched with one student in the control group $(n=1681)$ to create a balanced model. A chi square test after matching showed no significant imbalance remaining after matching, $\chi^{2}$ $(15)=13.2, p=.59$. Rosenbaum's sensitivity analysis showed that for $1: 1$ matching, $\Gamma \geq 1.20$, which suggests that at this point the association would no longer be significant between online enrollment and student course grades $(p=.12)$ or withdrawal rates $(p=.07)$.

The near-neighbor PSA with 1:2 matching used a similar method but matched each online student ( $n=1681$ ), with two face-to-face students $(n=3,362)$. This ratio kept a larger number of cases, but also decreased the balance. A follow-up chi square test showed a significant improvement in balance over the baseline but retained a significant level of imbalance between online and face-to-face groups, $\chi^{2}(15)=314, \mathrm{p}<0.001$. Sensitivity analysis showed that when $\Gamma \geq 1.20$, association would no longer be significant for course grades $(p=.14)$ and for withdrawal rates $(p=.07)$.

\section{Mahalanobis' Matching}

The next model tested with these data was the Mahalanobis' metric method. This method matched one face-to-face student $(n=1,681)$ with each online student $(n=1,681)$, to find the closest match for each student using a different matching model. This method showed improvement on balance, but a chi square test showed that there was still a significant remaining imbalance between groups, $\chi^{2}(15)=98.3, p<0.001$. This model was highly sensitive to missing data, as when $\Gamma \geq 1.05$, there was no longer a significant association between course enrollment and grades $(p=.09)$, or withdrawal rates $(p=.05)$.

\section{Optimal Matching}

The final statistical model tested with these data was optimal matching with a 1:1 and a 1:3 ratio. Optimal 1:1 matching again matched one online student $(n=1,681)$ with a similar faceto-face student $(n=1,681)$, using a method that estimates the best fit for all of the data. The 1:1 model was not able to fully eliminate the imbalance between groups, and although it showed significant improvement, a follow-up chi square test showed a remaining statistically significant imbalance after matching, $\chi^{2}(15)=232, p<0.001$. Sensitivity tests suggest that when $\Gamma \geq 1.20$, the association between online enrollment and course grades would no longer be significant $(p=$ .08 ). For the association between online enrollment and withdrawal rates, sensitivity to hidden bias was even higher, as when $\Gamma \geq 1.15$, the association would no longer be significant $(p=.10)$.

Optimal matching with a 1:3 ratio retained the most cases, as online students $(n=1,681)$ were each matched with three face-to-face students $(n=5,043)$. This had a negative impact on balance between groups, with the smallest change in balance of all models tested. A chi square test showed the significant imbalance that remained after matching, $\chi^{2}(15)=987, p<0.001$. This model also showed the most sensitivity to hidden bias: when $\Gamma \geq 1.05$, the association would no longer be significant between course modality and student grades $(p=.09)$. Similarly, when $\Gamma \geq 1.15$ the association between course enrollment and withdrawal rates would no longer be significant $(p=.10)$.

\section{Model Selection and Results}

Given the differences between these three models, the researcher examined each for the best fit for these data, comparing case retention, balance, and sensitivity to hidden bias. Using these measures for validity and sensitivity, the near-neighbor 1:2 matching was selected as the 
most robust model. This model retained a higher number of cases than the 1:1 matching techniques, including the Mahalanobis metric. This made it a better choice than the nearneighbor 1:1 matching model, despite having greater imbalance. The near-neighbor 1:2 matching model did see an improvement in matching for all but one of the eight unbalanced covariates identified in the baseline data. Finally, this model had was less sensitive to hidden bias than all but one of the other tested models, with a score of $\Gamma \geq 1.20$ for both student grades and withdrawal rates.

Using the near-neighbor 1:2 matching PSA, the researcher conducted final two-sample $t$ tests on these matched results to determine the effect of online course enrollment on student course outcomes. The first research question was about the impact of online course enrollment on course grades. After matching, there was no statistically significant difference between online and face-to-face students with regards to their composite GPA, $t(3067)=1.17, p=0.24$. These results contrasted with baseline results, which had indicated a higher GPA for online students $(m$ $=2.55)$ than for face-to-face students $(m=2.34), t(7763)=-5.80, p<.001$. See figure 3 .

\section{Figure 3.}

Boxplot of student average GPA based on course enrollment after near-neighbor 1:2 matching.

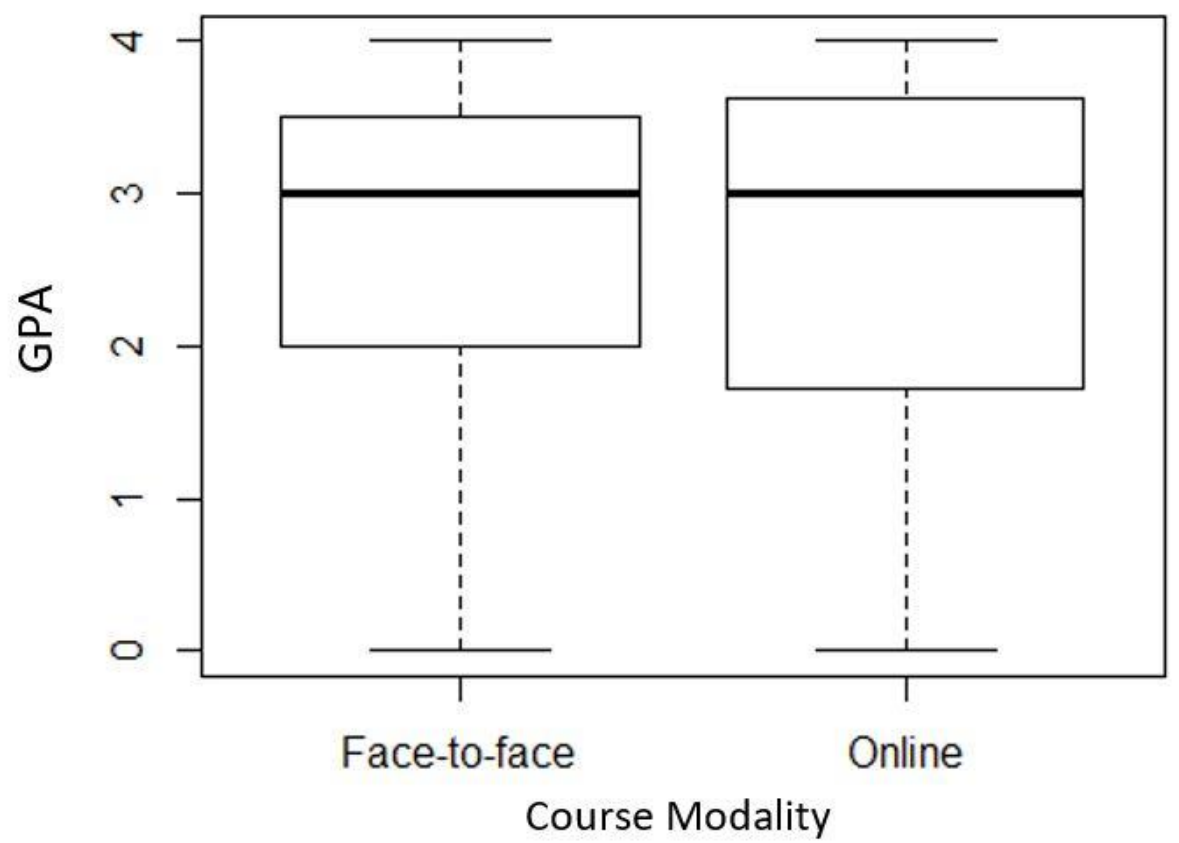

To answer the second research question about the effect of online course enrollment on course withdrawal rates, the researcher again used a two-sample $t$-test after using near-neighbor 1:2 matching, the results of which indicated that online students had significantly higher withdrawal rates $(m=0.09)$ than did face-to-face students $(m=0.07), t(5041)=-2.76, p<.01)$. Again, these results contrasted with baseline data, which had suggested that there was no significant difference between withdrawal rates based on course enrollment decisions $t(7763)=-1.07, p=$ 0.28). See Figure 4. 


\section{Figure 4.}

Bar chart of student withdrawal rates based on course enrollment after near-neighbor 1:2 matching.

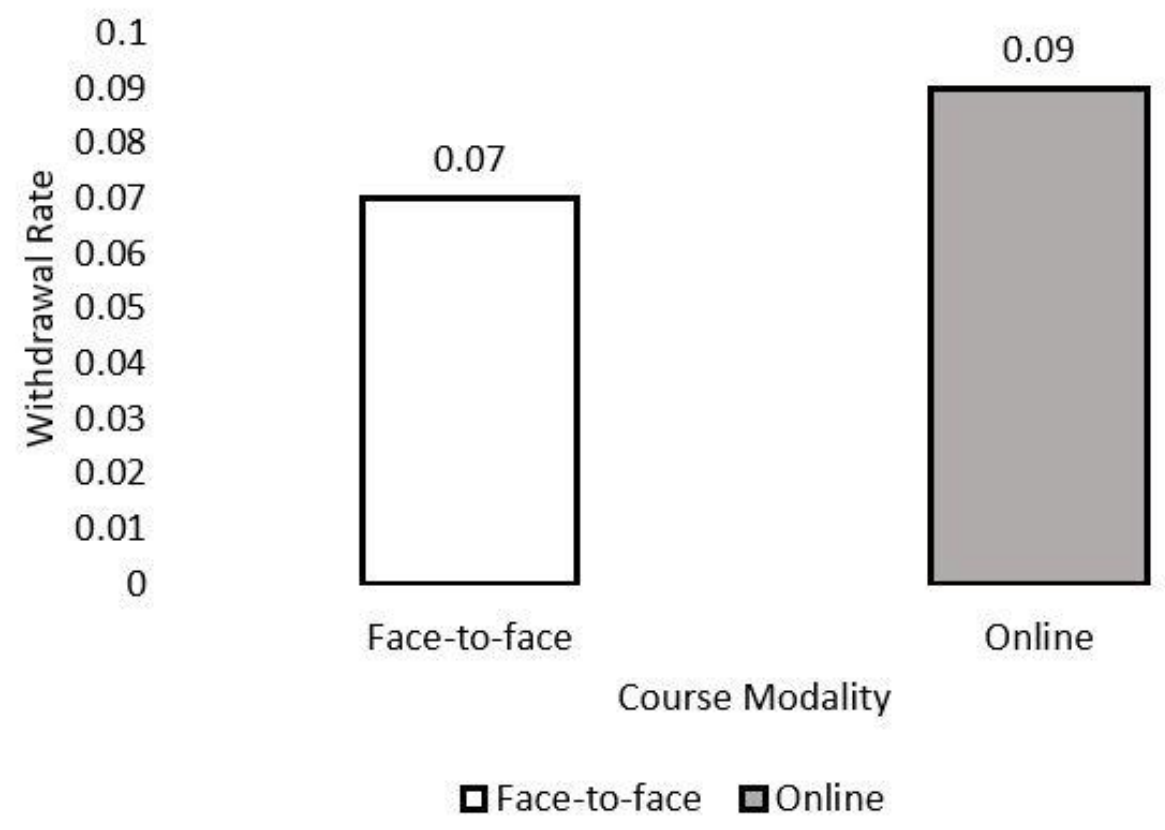

In considering these results, it is important to consider the sensitivity of these tests to hidden bias. In both cases, when $\Gamma \geq 1.20$, the association between course grades $(p=.14)$ and withdrawal rates $(p=.07)$ and online course enrollment would no longer be significant. This suggests that the odds of these results occurring as a result of course enrollment rather than at random is only 1.2, or that these outcomes are only 1.2 times more likely to occur as an effect of course enrollment than they are to happen randomly. This is not a robust result and indicates the possibility of one or more source of hidden bias, or other confounding covariates that may be missing from the model that would impact student success in online courses.

\section{Discussion}

This study used a propensity score analysis method as a robust statistical test to estimate causality in determining the effect of student enrollment in online courses. In circumstances where it is impractical to conduct a randomized control trial, such as observational studies in higher education, the PSA can provide a statistical method to approximate these results by balancing out the selection bias introduced by student self-enrollment into online or face-to-face courses.

\section{Baseline Data Compared to PSA Results}

The contrast between baseline results and results from the PSA validate theory by Tinto (1975, 1993) and Rovai (2003), who posit that student characteristics, including demographic, academic and personal factors all contribute to student success in higher education. Baseline results indicated a statistically significant imbalance between online and face-to-face student groups. Prior to balancing that sample, students enrolled primarily in online classes had significantly higher grades than did face-to-face students, and the two groups had no significant 
difference in withdrawal rates. However, after balancing the sample and accounting for 15 confounding covariates, results of a near-neighbor 1:2 matching technique demonstrated that while online and face-to-face students had no significant difference in course grades, online students did have significantly higher withdrawal rates. The reason for this disparity between baseline and PSA results may be that students who enroll in online classes tend to be older, have more academic experience, and better past academic performance.

\section{Student Course Grades}

A result of no significant difference in course grades between the two groups is particularly relevant in this context. It supports the idea of the no significant difference phenomenon developed by Russell (1999), and a large body of literature that suggests that there is no significant difference in online course outcomes when compared with face-to-face classes (Dellana et al., 2000; Gutierrez \& Russo, 2005; Leasure et al., 2000; McDonough, et al., 2014; Reuter, 2009; Rivera \& Rice 2002; Summers et al., 2005; Waschull, 2001; Werhner, 2010). This study is unique in scope, however, with a larger sample size from an institutional dataset that incorporated data across many disciplines and used a robust statistical method to evaluate results by accounting for selection bias.

\section{Student Withdrawal Rates}

In contrast to the above results related to student course grades, this study found that after near-neighbor 1:2 matching, online students had significantly higher withdrawal rates than faceto-face students, while the baseline data had found no significant differences between the two groups. A current body of literature has found better course performance in face-to-face classes, but none of the studies reviewed here specifically examined student withdrawal rates (Arias et al., 2018; Bunn et al., 2014; Johnson \& Palmer, 2015; Kaupp, 2012; Verhoeven \& Wakeling, 2011). Interestingly, the results from this current study did echo the consistent results found in the three previous studies using a robust PSA, which also found higher withdrawal rates among online students (Smith, 2017; Xu and Jaggars, 2011a, 2011b).

\section{Student Outcomes and the Student Integration Model}

Previous research has generally used a simple statistical analysis that fails to control for characteristics identified in the student integration model (Rovai, 2003; Tinto, 1975, 1993). This body of research typically controlled for only one to five covariates (Dellana et al., 2000; Gutierrez \& Russo, 2005; Leasure et al., 2000; McDonough et al., 2014; Reuter, 2009; Rivera \& Rice, 2002; Summers et al., 2005; Waschull, 2001; Werhner, 2010), with some research failing to control for any additional covariates in their study design (Gutierrez \& Russo, 2005; McDonough et al., 2014; Rivera \& Rice, 2002; Summers et al., 2005). The disparity between baseline results from the current study with results from a more robust PSA that controls for 15 confounding covariates indicates the importance of accounting for a wide variety of student characteristics in research related to online learning.

\section{Limitations}

Propensity score analysis is highly sensitive to missing data (Guo \& Fraser, 2015). As a result, this research used a list-wise strategy to delete any student cases that were missing data. Four covariates from the study had missing data: first-generation status, ACT scores, high school GPA, and income. The only covariate with missingness that contributed to imbalance in the model was ACT scores, but deleting these cases reduced the number of total cases in the study. Deleting cases in this way may have introduced additional bias, since the deleted cases were not missing completely at random (MCAR). 


\section{Implications}

The implications of these results could affect stakeholders at Russell and other large public HSIs. With the increase in online education over the past two decades (Allen \& Seaman, 2014; Seaman, Allen, \& Seaman, 2018) and a yet-to-be-determined long-term effect of the COVID-19 pandemic on online course enrollments, ensuring equitable access to education in both online and face-to-face modalities is important. This equitable access is particularly important at an HSI, where there has been limited research on the value of online learning for all students, and how it effects course outcomes for students at these institutions.

The statistically significant difference in withdrawal rates between online and face-toface students in this study is particularly concerning, and other research has suggested methods for supporting and engaging students at HSIs to improve retention and graduation rates (DiSanto \& Guevara, 2019; Espinosa \& Espinosa, 2012; Garcia \& Ramirez, 2018; Martin \& Meyer, 2010; Meling, 2012; Wolfe, Lyons \& Guevara, 2019). One way to do this is to ensure that students enrolled in both online and face-to-face classes are offered a way to develop collaborative relationships with faculty through personalized instruction and undergraduate research opportunities (Garcia \& Ramirez, 2018; Martin \& Meyer, 2010).

Faculty support and connection with online students can help improve retention, but so can adequate institutional support services for online students, such as academic advising, mental health services, registration, and financial aid (Espinosa \& Espinosa, 2012; Museus \& Ravello, 2010). Providing these services to all students, including online students, in a meaningful and personal way provides access to the social capital that many first-generation students lack (Garcia \& Ramirez, 2018). Fortunately, although there were gaps in availability of online support services pre-COVID-19, the pandemic has pushed institutions to provide additional, high-quality support for online students (Bouchey, Gratz \& Kurland, 2021; Sorrells \& Wittmer, 2020). While it is not yet known what the long-term availability of this support will be, the pandemic has pushed institutions to make greater efforts in supporting online students, which may have a positive impact on student retention in the future.

\section{Future Research}

This study attempts to fill a gap in research related to online course outcomes at HSIs but is still only part of a small body of research. The existing studies indicate an emerging pattern of unique student performance outcomes at HSIs (Wladis et al., 2015; Cottrell, 2020), but more research is needed to confirm this data pattern.

The results from the current study indicate that there is high sensitivity to hidden bias that could be impacting results. To add additional measures to balance this bias, future research could include a student survey that supplements institutional data. This survey could include measures such as information literacy, time management, social belonging, program fit, learning style, and student satisfaction as they relate to the student integration model (Rovai, 2003; Tinto, 1975, 1993). However, these factors may not be available in an institutional dataset. A survey could also introduce qualitative measures that help researchers better understand student withdrawal decisions. A mixed-method study would have a smaller sample size, but more robust data that allows for analysis of additional covariates that could impact student outcomes in online classes.

Finally, the COVID-19 pandemic has contributed to rapidly changing online environments, with additional supports for online students (Bouchey et al., 2021; Sorrells \& Wittmer, 2020), changing enrollment patterns and new course formats (Miller, 2021). These 
changes may have long lasting effects that impact student success in online classes both positively and negatively into the future. Future research should focus on these changes and compare pre-COVID-19 data with post-COVID-19 online student data to understand current trends and implications for online learning.

In summary, understanding student course outcomes through a robust statistical method shed new light on student performance at an HSI, and demonstrated the need for future research that controls for the selection bias inherent in an observational study. As the demand for online learning continues to grow, it is important to continue to improve our understanding of how to support diverse online learners in an equitable way.

\section{References}

Allen, I., \& Seaman, J. (2014). Grade change: Tracking online education in the United States. Pearson. http://www.onlinelearningsurvey.com/reports/gradechange.pdf

Amro, H. J., Mundy, M., \& Kupczynski, L. (2015). The effects of age and gender on student achievement in face-to-face and online college algebra classes. Research in Higher Education Journal, 27, 1-22.

Arias, J. J., Swinton, J., \& Anderson, K. (2018). Online vs. face-to-face: A comparison of student outcomes with random assignment. E-Journal of Business Education and Scholarship of Teaching, 12(2), 1-23.

Ashby, J., Sadera, W. A., \& McNary, S. W. (2011). Comparing student success between developmental math courses offered online, blended, and face-to-face. Journal of Interactive Online Learning, 10(3), 128-140.

Atchley, W., Wingenbach, G., \& Akers, C. (2013). Comparison of course completion and student performance through online and traditional courses. International Review of Research in Open and Distance Learning, 14(4), 104-116.

Bouchey, B., Gratz, E., \& Kurland, S. (2021). Remote student support during COVID-19: Perspectives of chief online officers in higher education. Online Learning, 25(1), 28-40. https://doi.org/10.24059/olj.v25i1.2481

Bunn, E., Fischer, M., \& Marsh, T. (2014). Does the classroom delivery method make a difference? American Journal of Business Education, 7(2), 143-150.

Camara, I. (2016). A comparison of academic performance in face-to-face, hybrid and online anatomy and physiology I courses at a college in south Texas. ProQuest Dissertations Publishing.

Cavanaugh, J. K., \& Jacquemin, S. J. (2015). A large sample comparison of grade based student learning outcomes in online vs. face-to-face courses. Online Learning, 19(2), 1-8. 
Coates, D., Humphreys, B., R., Kane, J., \& Vachris, M., A. (2004). "No significant distance" between face-to-face and online instruction: Evidence from principles of economics. Economics of Education Review, 23(5), 533-546.

doi://dx.doi.org.du.idm.oclc.org/10.1016/j.econedurev.2004.02.002

Cooper, L. W. (2001). A comparison of online and traditional computer applications classes. T.H.E.Journal, $28(8), 52$.

Cottrell, R. (2020). Student outcomes in online and face-to-face classes at a Hispanic-serving institution (HSI). ProQuest Dissertations Publishing.

Crisp, G., \& Nora, A. (2010). Hispanic student success: Factors influencing the persistence and transfer decisions of Latino community college students enrolled in developmental education. Research in Higher Education, 51(2), 175-194.

Dellana, S. A., Collins, W. H., \& West, D. (2000). On-line education in a management science course--effectiveness and performance factors. Journal of Education for Business, 76(1), 43-47.

DiSanto, J. M., \& Guevara, C. (2019). The online learning initiative: Training the early adopters. In K. Wolfe, K. Lyons, C. Guevara (Eds.), Developing educational technology at an urban community college (pp. 79-93). SpringerLink, \& LINK.

Dotterweich, D. P., \& Rochelle, C. F. (2012). Online, instructional television and traditional delivery: Student characteristics and success factors in business statistics. American Journal of Business Education, 5(2), 129-138.

Espinoza, Penelope P., \& Espinoza, Crystal C. (2012). Supporting the 7th-year undergraduate: Responsive leadership at a Hispanic-serving institution. Journal of Cases in Educational Leadership, 15(1), 32-50.

Euzent, P., Martin, T., Moskal, P., \& Moskal, P. (2011). Assessing student performance and perceptions in lecture capture vs. face-to-face course delivery. Journal of Information Technology Education, 10, 295-307.

Excelencia in Education. (2019). Latinos in higher education: Compilation of fast facts. https://www.edexcelencia.org/research/publications/latinos-higher-education-compilation-fastfacts

Figueira, R. (2015). The applicability of Tinto's model of student retention in online learning: A faculty perspective. ProQuest Dissertations Publishing.

Flores, S. M., \& Park, T. J. (2015). The effect of enrolling in a minority-serving institution for Black and Hispanic students in Texas. Research in Higher Education, 56(3), 247-276. 
Garcia, G. A., \& Ramirez, J. J. (2018). Institutional agents at a Hispanic serving institution: Using social capital to empower students. Urban Education, 53(3), 355-381. https://doi.org/10.1177/0042085915623341

Green, E. (2020, March 10). Rules eased on colleges seeking to close their campuses amid outbreak. The New York Times. https://www.nytimes.com/2020/03/10/us/politics/coronaviruscolleges.html?searchResultPosition=5

Gregory, C. B., \& Lampley, J. H. (2016). Community college student success in online versus equivalent face-to-face courses. Journal of Learning in Higher Education, 12(2), 63-72.

Gulacar, O., Damkaci, F., \& Bowman, C. R. (2013). A comparative study of an online and a face-to-face chemistry course. Journal of Interactive Online Learning, 12(1), 27-40.

Guo, S., \& Fraser, M. (2015). Propensity score analysis. Sage.

Gutierrez, D., \& Russo, S. (2005). Comparing student performance, attitudes and preferences in an introduction to business course: Online, hybrid and traditional delivery methods - who makes the "A" grade? College Teaching Methods \& Styles Journal, 1(3), 83-90.

Hurlbut, A. R. (2018). Online vs. traditional learning in teacher education: A comparison of student progress. American Journal of Distance Education, 32(4), 248-266.

doi://dx.doi.org.du.idm.oclc.org/10.1080/08923647.2018.1509265

Hurtado, S., \& Ponjuan, L. (2005). Latino educational outcomes and the campus climate. Journal of Hispanic Higher Education, 4(3), 235-251.

Johnson, D., \& Palmer, C. C. (2015). Comparing student assessments and perceptions of online and face-to-face versions of an introductory linguistics course. Online Learning, 19(2), 1-18.

Jorczak, R. L., \& Dupuis, D. N. (2014). Differences in classroom versus online exam performance due to asynchronous discussion. Journal of Asynchronous Learning Networks, 18(2), 1-9.

Kaupp, R. (2012). Online penalty: The impact of online instruction on the Latino-white achievement gap. Journal of Applied Research in the Community College, 19(2), 8-16.

Kelly, A. P., Schneider, M., \& Carey, K. (2010). Rising to the challenge: Hispanic college graduation rates as a national priority. American Enterprise Institute for Public Policy Research. https://files.eric.ed.gov/fulltext/ED508846.pdf

Kim, J. (2020, April 1). Teaching and learning after COVID-19:Three post-pandemic predictions. Inside Higher Ed. https://www.insidehighered.com/digital-learning/blogs/learninginnovation/teaching-and-learning-after-covid-19och, J. (2005a). Does distance learning work? A large sample, control group study of student success in distance learning. E-Journal of Instructional Science and Technology, 8(1), 1-21. 
Koch, J. (2005b). The influence of ethnic background, gender and age on student performance in distance learning programs. Journal of Educational Technology, 2(3), 38-49.

LaMeres, B. J., \& Plumb, C. (2014). Comparing online to face-to-face delivery of undergraduate digital circuits content. IEEE Transactions on Education, 57(2), 99-106.

doi://dx.doi.org.du.idm.oclc.org/10.1109/TE.2013.2277031

Lapsley, R., Kulik, B., Moody, R., \& Arbaugh, J. B. (2008). Is identical really identical? An investigation of equivalency theory and online learning. Journal of Educators Online, 5(1), 1-19.

Larson, D. K., \& Sung, C. (2009). Comparing student performance: Online versus blended versus face-to-face. Journal of Asynchronous Learning Networks, 13(1), 31-42.

Leasure, A. R., Davis, L., \& Thievon, S. L. (2000). Comparison of student outcomes and preferences in a traditional vs. world wide web-based baccalaureate nursing research course. Journal of Nursing Education, 39(4), 149-54.

Leite, W. (2017). Practical propensity score methods using R. Sage.

Martin, N. K., \& Meyer, K. (2010). Efforts to improve undergraduate student retention rates at a Hispanic serving institution: Building collaborative relationships for the common good. College and University, 85(3), 40-49.

McCauley, A. (2020, April 10). How COVID-19 could shift the college business model: 'It's hard to go back.' Forbes. https://www.forbes.com/sites/alisonmccauley/2020/04/09/how-covid19-could-shift-the-college-business-model/\#406361a9564f

McDonough, C., Roberts, R. P., \& Hummel, J. (2014). Online learning: Outcomes and satisfaction among underprepared students in an upper-level psychology course. Online Journal of Distance Learning Administration, 17(3).

Meling, V. (2012). The role of supplemental instruction in academic success and retention at a Hispanic-serving institution, ProQuest Dissertations and Theses.

Miller, C. (2021, March 14). Online education statistics. Educationdata.org. https://educationdata.org/online-education-statistics

Museus, S. D., \& Ravello, J. N. (2010). Characteristics of academic advising that contribute to racial and ethnic minority student success at predominantly White institutions. NACADA Journal, 30(1), 47-58.National Center for Education Statistics, U.S. Department of Education. (2019). Digest of Education Statistics 2019, Table 311.15. https://nces.ed.gov/programs/digest/d19/tables/dt19_311.15.asp

National Center for Education Statistics, U. S. Department of Education. (2012). Higher education: Gaps in access and persistence study. https://nces.ed.gov/pubs2012/2012046.pdf 
Reuter, R. (2009). Online versus in the classroom: Student success in a hands-on lab class. American Journal of Distance Education, 23(3), 151-162.

Rivera, J. C., McAlister, M. K., \& Rice, M. L. (2002). A comparison of student outcomes \& satisfaction between traditional \& web based course offerings. Online Journal of Distance Learning Administration, 5(3).

Rosenbaum, P. R. (2002). Observational studies (2nd ed). Springer.

Rosenbaum, P. R., \& Rubin, D. B. (1983). The central role of the propensity score in observational studies for causal effects. Biometrika, 70, 41-55.

Rovai, A. P. (2003). In search of higher persistence rates in distance education online programs. Internet and Higher Education, 6(1), 1-16. doi:10.1016/S1096-7516(02)00158-6

Russell, T. (1999). The no significant difference phenomenon: As reported in 355 research reports, summaries and papers. North Carolina State University Press.

Seaman, J., Allen, I., \& Seaman, J. (2018). Grade increase: Tracking distance education in the United States. Pearson. http://onlinelearningsurvey.com/reports/gradeincrease.pdf

Smith, N. (2017). Examining the effects of online enrollment on course outcomes using weighting procedures after multiple imputation on a state-wide university system. ProQuest Dissertations Publishing.

Sorrells, D., \& Wittmer, C. (2020). Reflections on transitioning to remote learning assistance during COVID-19 and possible implications for the future. In M. Frizell (Ed.), The learning assistance review: Special issue. Rising to the challenge: Navigating COVID-19 as higher education learning center leaders. (pp.41-48). National College Learning Center Association.

Summers, J. J., Waigandt, A., \& Whittaker, T. A. (2005). A comparison of student achievement and satisfaction in an online versus a traditional face-to-face statistics class. Innovative Higher Education, 29(3), 233-250. doi://dx.doi.org.du.idm.oclc.org/10.1007/s10755-005-1938-x

Tinto, V. (1993). Leaving college: rethinking the causes and cures of student attrition. University of Chicago Press.

Tinto, V. (1975). Dropout from higher education: A theoretical synthesis of recent research. Review of Educational Research, 45(1), 89-125. doi:10.3102/00346543045001089

Tseng, H., \& Walsh, E. J., Jr. (2016). Blended versus traditional course delivery: Comparing students' motivation, learning outcomes, and preferences. Quarterly Review of Distance Education, 17(1), 43-52.

Verhoeven, P., \& Wakeling, V. (2011). Student performance in a quantitative methods course under online and face-to-face delivery. American Journal of Business Education, 4(11), 61-66. 
Waschull, S. B. (2001). The online delivery of psychology courses: Attrition, performance, and evaluation. Teaching of Psychology, 28(2), 143-47.

Werhner, M. J. (2010). A comparison of the performance of online versus traditional on-campus earth science students on identical exams. Journal of Geoscience Education, 58(5), 310-312.

Wladis, C., Conway, K. M., \& Hachey, A. C. (2015). The online STEM classroom-Who succeeds? An exploration of the impact of ethnicity, gender, and non-traditional student characteristics in the community college context. Community College Review, 43(2), 142-164. doi:10.1177/0091552115571729

Wolfe, K., Lyons, K., \& Guevara, C., (Eds.). (2019). Developing educational technology at an urban community college. SpringerLink, \& LINK.

Xu, D., \& Jaggars, S. S. (2011a). The effectiveness of distance education across Virginia's community colleges: Evidence from introductory college-level math and English courses. Educational Evaluation and Policy Analysis, 33(3), 360-377. doi:10.3102/0162373711413814

Xu, D., \& Jaggars, S. S. (2011b). Online and hybrid course enrollment and performance in Washington state community and technical colleges. Community College Research Center Working Paper No. 31. Community College Research Center, Columbia University.

Xu, D., \& Jaggars, S. S. (2013). The impact of online learning on students' course outcomes: Evidence from a large community and technical college system. Economics of Education Review, 37, 46-57. doi:10.1016/j.econedurev.2013.08.001

Xu, D., \& Jaggars, S. S. (2014). Performance gaps between online and face-to-face courses: Differences across types of students and academic subject areas. The Journal of Higher Education, 85(5), 633-659. doi:10.1080/00221546.2014.11777343 